\title{
$020-021$ \\ Noticias y comentarios \\ Participación del IAPH en el X Congreso Internacional sobre Alteración y Conservación de Piedra
}

\section{PH50 - Octubre 2004}

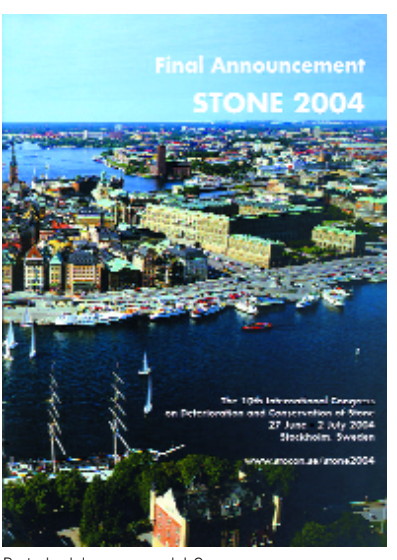

Portada del programa del Congreso
Durante los días 29 de junio a 2 de julio de 2004 se celebró en Estocolmo el X Congreso Internacional sobre Alteración y Conservación de Piedra, organizado por ICOMOS Suecia. Este congreso continúa una larga serie iniciada en 1972, con eventos cuatrienales celebrados en ciudades europeas.

El objetivo fundamental del Congreso fue la revisión del estado actual de conocimiento sobre la naturaleza y los mecanismos de deterioro de los materiales empleados en patrimonio inmueble, así como sobre los métodos de tratamiento que han sido aplicados, todo ello para determinar aquellos aspectos que deben estudiarse y desarrollarse en el futuro.

Las comunicaciones presentadas se agruparon en siete temas:

1. Deterioro de piedra y mortero

2. Propiedades y estructura de los materiales y su alteración

3. Métodos y productos de tratamiento

4. Métodos y técnicas de investigación para la conservación

5. Documentación

6. Casos prácticos, consideraciones éticas en conservación

7. Conservación y restauración de morteros en monumentos

Además se realizaron dos Sesiones de trabajo, una sobre Tratamientos hidrófugos y otra sobre Técnicas de limpieza de fachadas, además de una mesa redonda que ha tratado sobre la cooperación entre los distintos profesionales involucrados en el proceso de conservación.

El Instituto Andaluz del Patrimonio Histórico presentó una ponencia denominada "Caracterización de la piedra y evaluación de tratamientos para el Dolmen de Menga (Antequera, España)", que ha sido incluida dentro del área temática de casos prácticos.

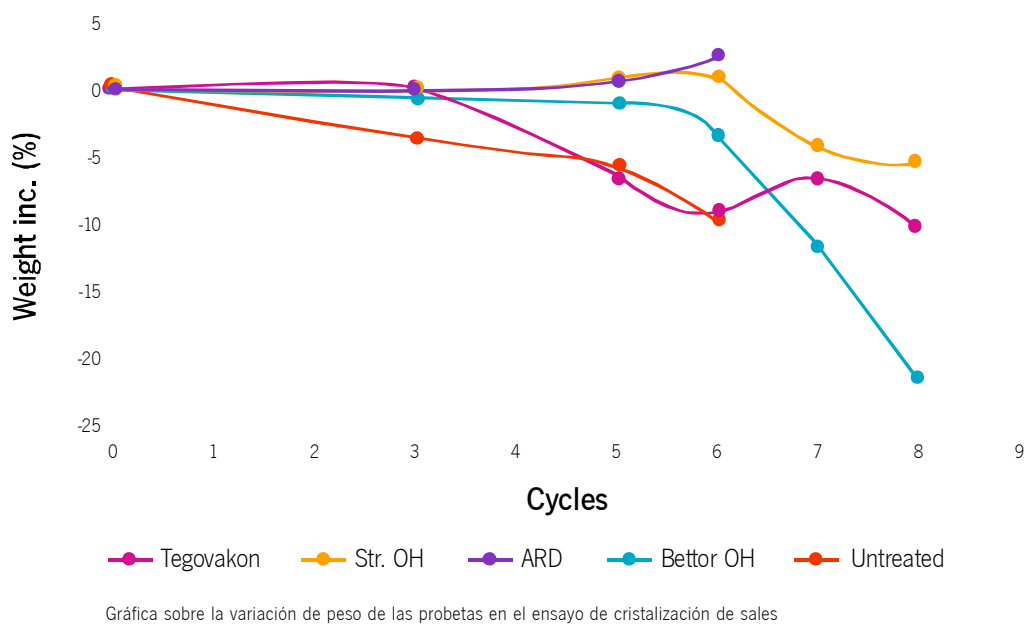

En esta ponencia se recogian los resultados del trabajo de investigación que se llevó a cabo en el Departamento de Análisis del IAPH en respuesta a la petición de la Delegación Provincial de Cultura de Málaga. Como consecuencia del estado de conservación del dolmen, se preparaba la intervención de restauración, para la cual se consideró necesario caracterizar el material pétreo y las alteraciones que sufria, así como evaluar el comportamiento de distintos productos de tratamiento previamente a su aplicación.

La piedra empleada principalmente en el dolmen es una caliza bioclástica poco cementada y los indicadores de alteración que se presentan se deben tanto a sus características intrínsecas como a factores externos: costra carbonatada distribuida irregularmente cubriendo material relativamente disgregado, pérdidas de material en las zonas bajas debidas a la humedad de capilaridad, costras oscuras con yeso, muy compactas y poco permeables, eflorescencias y sales en zonas bajas y fracturas siguiendo el lecho de sedimentación de la roca.

Ante el estado de decohesión de la piedra en zonas relativamente amplias se planteó la posibilidad de aplicar tratamientos consolidantes para mejorar la resistencia de la piedra. En el estudio realizado se seleccionaron cuatro productos, con los cuales se trataron probetas preparadas con material de cantera. En estas probetas se determinaron propiedades relacionadas con la absorción de agua, así como la variación en las propiedades mecánicas, midiéndose esta última de forma indirecta a través de la variación en la velocidad de ultrasonidos.

Para determinar la resistencia de la piedra tratada frente a los factores de deterioro, que son fundamentalmente la humedad y las sales solubles, se sometieron las probetas al ensayo de cristalización de sales. Pudo comprobarse que ninguno de los tratamientos mejoraba el comportamiento intrínseco de la piedra, que depende fundamentalmente de sus características (lecho de sedimentación muy marcado). Por ello, la conclusión extraída del trabajo ha sido la no conveniencia de aplicar ningún tratamiento, ya que no se obtenían mejoras significativas en la evolución futura de la piedra.

Rosario Villegas Sánchez

Dpto. de Ingeniería Química y Ambiental Escuela Superior de Ingenieros de Sevilla 